\title{
Estimation of Fire Danger in Hawai'i Using Limited Weather Data and Simulation ${ }^{1}$
}

\author{
David R. Weise, ${ }^{2,4}$ Scott L. Stephens, ${ }^{3}$ Francis M. Fujioka, ${ }^{2}$ Tadashi 7. Moody, ${ }^{3}$ and Fohn Benoit ${ }^{2}$
}

\begin{abstract}
The presence of fire in Hawai'i has increased with introduction of nonnative grasses. Fire danger estimation using the National Fire Danger Rating System (NFDRS) typically requires 5 to $10 \mathrm{yr}$ of data to determine percentile weather values and fire activity. The U.S. Army Pōhakuloa Training Area in Hawai' $i$ is located in the interface zone between windward and leeward weather conditions and needed to develop fire danger values but did not have sufficient weather or fire occurrence data. Use of simulation to estimate fire danger (expressed as fire risk) for areas with limited weather data was investigated. Influence of spatial resolution of weather information on fire risk was examined by comparing fire risk calculated using one or three weather stations and gridded weather predictions from the Mesoscale Spectral Model. Predicted gridded temperature was positively correlated with observed temperature; predicted and observed relative humidity were not significantly correlated. Simulated fire risk differed between weather data percentiles and between weather data resolutions. Predicted risk estimated from gridded weather data agreed more closely with observed risk estimated from weather data observed at all three remote automated weather stations. Correlation between simulated fire risk and the NFDRS Ignition Component was statistically significant for the single weather station simulations. Correlations between risk and the Ignition Component were not statistically significant for the three station and gridded weather data scenarios, which illustrates the difference between fire danger determined at broad spatial scales and fire risk resolved at finer spatial scales. Fire spread simulation modeling to estimate fire risk in areas with limited historical weather and fire occurrence data can provide finer-scale information than the NFDRS, which is better suited to larger, homogeneous areas with more complete fire and weather data. Values for the NFDRS Burning Index were determined and incorporated into the wildland fire management plan for Pōhakuloa Training Area.
\end{abstract}

${ }^{1}$ Logistical support and funding for this study was provided by the U.S. Army Garrison-Hawaii, Schofield Barracks. The paper was prepared by U.S. Government employees on official time with government funding and is therefore in the public domain and not subject to copyright laws. Manuscript accepted 23 June 2009.

${ }^{2}$ U.S. Department of Agriculture Forest Service, PSW Research Station, Forest Fire Laboratory, 4955 Canyon Crest Drive, Riverside, California 92507.

${ }^{3}$ University of California, College of Natural Resources, Department of Environmental Science, Policy, and Management, Berkeley, California 94720.

${ }^{4}$ Corresponding author (e-mail: DWeise@fs.fed.us).

Pacific Science (2010), vol. 64, no. 2:199-220

doi: 10.2984/64.2.199

Work of the U.S. Government

Not under copyright
WildLAND FIRE is an integral component of many terrestrial ecosystems within and surrounding the Pacific Ocean. In Hawai' $i$, the role that fire has played in the evolution of the island biota is still a matter of some debate. Although volcanism has played a prominent role in the formation of the Islands, the prehistoric extent of fire caused by lightning and/or lava is unknown. It is known that the arrival of Polynesian people in Hawai'i circa 400 A.D. resulted in dramatic changes to the vegetation as a result of intensive cultivation and the introduction of preferred cultural plants and animals (Loope 2000). The "discovery" of the Hawaiian Islands by European countries beginning in the late 1700 s resulted 
A

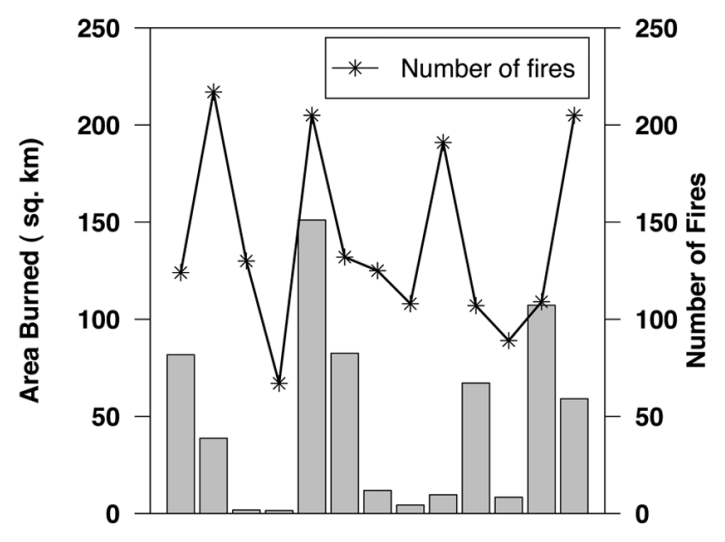

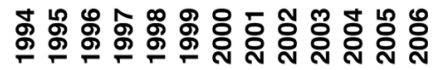

Year
B

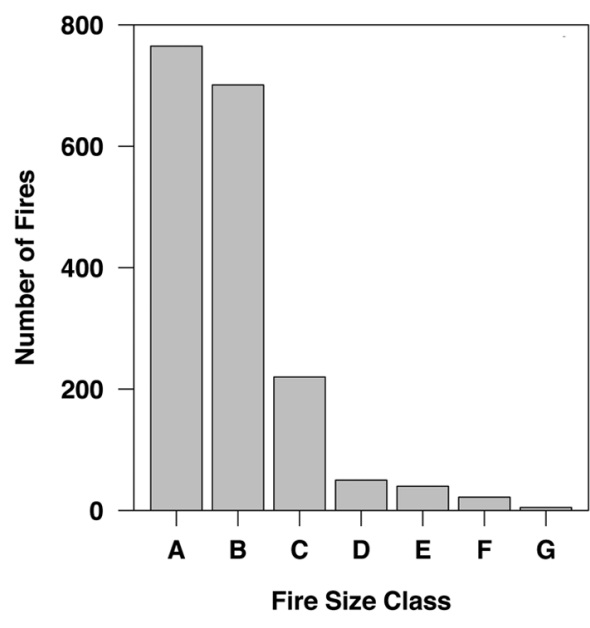

FigURE 1. Fire statistics for state-protected lands in Hawai'i from 1994 to 2006. $A$, Annual area burned and number of fires; $B$, fire size distribution: class A, 0.1 ha or less; B, 0.1 to 3.9 ha; $C, 4.0$ to 40.0 ha; $\mathrm{D}, 40.1$ to 121.4 ha; E, 121.5 to 404.8 ha; F, 404.8 to 2,023.9 ha; G, 2,024 ha or more. Annual area burned is highly variable, with a small, but important, number of large fires $\left(100 \mathrm{ha}=1 \mathrm{~km}^{2}\right)$.

in yet another dramatic change in vegetation with the introduction of a large number of plant, animal, insect, and disease species (Cuddihy and Stone 1990). In particular, nonnative grasses were introduced from several locations around the world for a variety of purposes including fodder for grazing animals (Maly and Wilcox 2000). All of these changes have resulted in an environment that is favorable to fire occurrence (D'Antonio and Vitousek 1992).

Wildfire has presented an important hazard in Hawai'i for at least $40 \mathrm{yr}$. A single fire burned nearly 15,800 ha in September 1967 on the island of Hawaici (Burgan et al. 1974), and mean annual burned area under state protection was 5,670 ha for the period 1967-1972. Mean annual burned area under state protection from 1994 to 2006 was 4,808 ha (Hawai'i Department of Land and Natural Resources 2007) (Figure 1). The annual area burned was highly variable (coefficient of variation $[\mathrm{CV}]=0.99$ ); however, variability about the mean annual number of fires (139) was smaller $(\mathrm{CV}=0.49)$. The majority of fires that occurred on state-protected lands were small (less than 3.9 ha), but five fires greater than 2,024 ha occurred during this time period.

Much of the lowland vegetation in Hawai' $i$ has been changed by human settlement and the introduction of nonnative plants, but there are several refugia located throughout the Islands where native vegetation still dominates. These refugia tend to be located at higher elevations and are protected by either state or federal landowners. On the island of Hawai' $i$, the U.S. Army manages the 42,600 ha Pōhakuloa Training Area (PTA) (Figure $2 A$ ), which contains the Kippuka Kâlawamauna Endangered Plant Area (Shaw et al. 1997) and a portion of the designated critical habitat for the endangered forest bird palila (Loxioides bailleui). The palila lives exclusively in the māmane (Sophora chrysophylla) and naio (Myoporum sandwicense) forest of Mauna Kea (U.S. Fish and Wildlife Service 1986). Over the past $20 \mathrm{yr}$, several large fires have originated near the coast and burned upslope, threatening the valuable natural resources in PTA. An effort to assemble the necessary information was undertaken by the Army in 

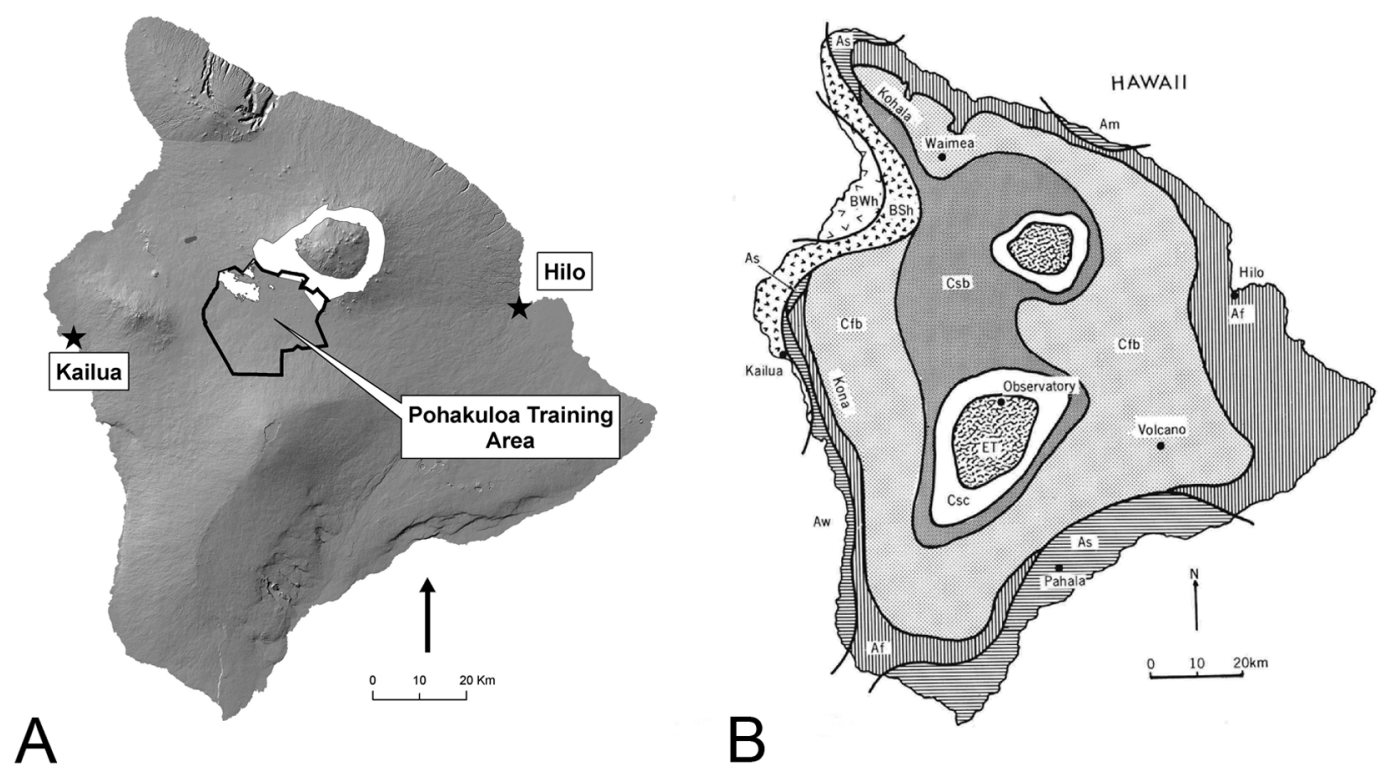

Figure 2. $A$, Pōhakuloa Training Area (PTA) is located in the saddle between Mauna Kea and Mauna Loa volcanoes on the island of Hawai i. Palila critical habitat and endangered plant habitats indicated in white. $B$, Köppen climate zone map of Hawaici illustrating wide range of climate types (adapted from fig. 2 of Juvik et al. [1978]). PTA falls within the $\mathrm{Cfb}$ (mild with no dry season, warm summer) and Csb (mild with dry, warm summer) zones. Interested readers are referred to Juvik et al. (1978) for descriptions of climate types.

1997 to develop a fire management plan for PTA that utilized National Fire Danger Rating System (NFDRS) indices to regulate training activities (U.S. Army 2003). However, no fire occurrence data and limited weather data were available to predict fire danger indices, which were a required component of the fire management plan (Beavers and Burgan 2002). The U.S. Army contracted with the Forest Service to analyze weather, fuel, and fire conditions at PTA to develop fire danger indices to be used to regulate training activities. This paper describes the various analyses we performed to develop the NFDRS index values given the paucity of data in existence in 1998. The paper also describes the effects of weather data type on simulated fire risk.

\section{Literature Review}

In the United States, the NFDRS was developed to describe the combination of both constant and variable factors that affect the initiation, spread, and difficulty of control of wildfires in a broad geographic area. Fire danger was defined as a combination of fuel, weather, topography, and risk (National Wildfire Coordinating Group 2002). In the NFDRS, risk contained two components: lightning and human-caused. Currently, the NFDRS is used in the lower 48 states, a portion of Alaska, and specific locations in Hawai'i. In Hawai'i, the NFDRS was implemented statewide for a few years in the early 1980s; a high-resolution version that includes high-resolution predicted weather is now implemented (Fujioka et al. 2000).

The NFDRS integrates fuel, weather, topography, and ignition characteristics into an index-based system to describe fire potential. The fire behavior indices of the system (Spread Component, Energy Release Component, and Burning Index) are determined by fuel and weather properties and based on equations developed by Byram (1959), Rothermel (1972), and Albini (1976). The Spread Component is equal to the rate of spread 
predicted by the Rothermel model, and the Burning Index is equal to the predicted flame length multiplied by 10 . The Burning Index is predicted using the Spread Component and the Energy Release Component. The weighting assigned to the individual fuel bed components differs between fire behavior and fire danger calculations so there is some numerical difference between rate of spread and the Spread Component (Cohen and Bradshaw 1986). These indices contain no probabilistic component. The Ignition Component index is one of three indices that model fire occurrence (Cohen and Deeming 1985). It is composed of two probabilities: (1) the probability that an ignition source will start a fire in dead fine fuels, and (2) the conditional probability that a reportable fire will result, given the Spread Component. The probability of ignition is a function of $1 \mathrm{hr}$ fuel moisture, and the probability of a reportable fire is proportional to the square root of the Spread Component. A variable called state-of-the-weather describes the cloudiness of the sky and precipitation occurrence and is used in fuel moisture calculations. The physical characteristics of fuel beds are described by a set of parameters that collectively are called a fuel model (Deeming et al. 1977). The original implementation of the NFDRS in 1972 used only nine fuel models (Deeming et al. 1972). Twenty fire danger fuel models (denoted A-T [Deeming et al. 1977]) are now used throughout the United States. Thirteen fire behavior (denoted 1-13 [Albini 1976]) fuel models were generally used to describe fuel beds in the United States before the advent of "custom" fire behavior fuel models (Burgan 1987), the expanded fire behavior fuel models of Scott and Burgan (2005), or the Fire Characteristics Classification System (Ottmar et al. 2007).

Monte Carlo simulation has been used to simulate fire hazard and to estimate fire risk and predict ecological fire regimes when actual data are scarce. Fire behavior simulation is used to represent the wildfire hazard. Multiple simulations of fire behavior are used to estimate fire risk (the probability that a wildfire will burn a particular location or release a certain amount of energy). The gen- eral approach that has been used throughout the world is to repeatedly simulate the spread of fire across a landscape of interest and to then estimate various statistical properties of fire occurrence (size, fire return interval, probability of occurrence, fire intensity, etc.). Several different fire spread models have been incorporated into these simulation systems. Perhaps the Rothermel fire spread model (Rothermel 1972, Albini 1976) has been most widely applied throughout the world due to its simplicity (for example, Finney [1998], Farris et al. [2000], Perry et al. [1999], LaCroix et al. [2006], Ager et al. [2007], Carmel et al. [2009]); however, other fire spread models have also been used (Parisien et al. 2005, Suffling et al. 2008). The Rothermel fire spread model was developed by making several simplifying assumptions about fuel and weather that affect its accuracy in real-world application. To gain a detailed understanding of the Rothermel model, its limitations, and its implementation as part of the FARSITE fire spread simulator, interested readers are referred to Rothermel (1972), Albini (1976), and Finney (1998). The coupling of fire simulators with vegetation simulators is an active area of current research worldwide (Fosberg et al. 1999). Various simulation techniques and models have been developed and compared to simulate changes in fire occurrence and vegetation distribution as a result of climate change or vegetation management activities. For recent reviews of the various models and approaches used in this area, interested readers are referred to Cary et al. (2006), Keane et al. (2003), and Keane et al. (2004).

In addition to the NFDRS indices listed previously, the Keetch-Byram Drought Index (KBDI) (Keetch and Byram 1968) was incorporated into the 1988 revision of the NFDRS. The KBDI essentially estimates the soil water deficit and ranges between 0 and 800 (0 to $20.32 \mathrm{~cm}$ ). In a 17 -month study, Burgan (1976) found that KBDI correlated well with fuel moisture content of the grass Pennisetum setaceum and the native shrub Dodonaea viscosa in Hawai'i $(r=-0.82$ and -0.84 , respectively); however, correlation with Andropogon virginicus was poor $(r=$ 
-0.21). Dolling et al. (2005) reported a strong correlation between KBDI and monthly total area burned from 1976 to 1996 for the islands of $\mathrm{O}^{\prime} \mathrm{ahu}, \mathrm{Maui}$, and Hawai'i.

Fuel loads of introduced grasses in Hawai' $i$ have recently been described (Wright et al. 2002, Elmore et al. 2005), and moisture dynamics of the grasses in response to diurnal changes has also been described (Weise et al. 2005). The fuel loads reported for the grass fuels sampled in Hawai'i greatly exceeded modeled fuel loads for grass fire behavior or fire danger fuel models in some instances. Fuel model $\mathrm{N}$ represents the highest grass fuel load in the NFDRS; it was designed to represent sawgrass (Cladium jamaicense), which grows in the Florida Everglades (Andrews et al. 2003). The fuel load in the $1 \mathrm{hr}$ and $10 \mathrm{hr}$ time lag fuel size classes for model $\mathrm{N}$ is $6.7 \mathrm{Mg} / \mathrm{ha}$. This fuel load is similar to that reported by Blackmore and Vitousek (2000) for Pennisetum clandestinum $(7.7 \mathrm{Mg} /$ ha) and by Freifelder et al. (1998) for Schizachyrium condensatum $(5.7 \mathrm{Mg} / \mathrm{ha})$. In contrast, Wright et al. (2002) reported fuel loads for Pennisetum setaceum up to $15.9 \mathrm{Mg} / \mathrm{ha}$ and $21.1 \mathrm{Mg} / \mathrm{ha}$ for Urochloa maxima.

Weather data are required to estimate fire risk using the NFDRS. The weather station network on the island of Hawai' $i$ is located primarily in the lower-elevation areas near the coast (Giambelluca and Schroeder 1998). The PRISM group at Oregon State University recently (2006) produced gridded maps of precipitation and temperature for Hawai' $i$ (http://www.prism.oregonstate.edu/products/ pacisl.phtml) based on data from 1971 to 2000, but those maps were not available at the time of this study, nor are the data they provide sufficient for NFDRS index calculations. Many of the weather stations do not include all of the necessary components required of a fire danger rating system weather station (Finklin and Fischer 1990), such as a fuel moisture stick array that is used to estimate fuel moisture content of $10 \mathrm{hr}$ time lag fuels. Even though the U.S. National Park Service established fire danger rating weather stations within $50 \mathrm{~km}$ of PTA, these stations were not located in the same climate zone as PTA due to the diverse climatic zones in Hawai'i (Figure 2B). PTA is located in the Köppen temperate climate zones (Cfb, continuously wet warm temperate; Csb, summer-dry warm temperate), which have at least 4 months with mean temperatures between 10 and $22^{\circ} \mathrm{C}$. Seventy percent of the annual rainfall occurs in the six winter months and the driest summer month has less than $3 \mathrm{~cm}$ of rainfall in the Csb climate. As a result, the vegetation types at PTA are different from the vegetation found in the national parks, and the fire danger indices and analyses available from the National Park Service were not applicable to PTA.

The management objective of this study was to derive values of NFDRS indices to be used to manage military training activities at PTA while reducing fire risk to the biological resources. No fire data (size and occurrence) were available for use at the time of the study (1998), so we chose to use fire spread simulations to generate area burned under various weather conditions. The simulation study consisted of three phases: (1) determination of weather conditions associated with three levels of fire danger using existing weather data, (2) simulation of fire risk for the three fire danger levels using a fire spread simulator, and (3) evaluation of the effect of weather data resolution on simulated fire risk.

\section{MATERIALS AND METHODS}

\section{Determination of Fire Danger Weather Conditions}

Levels of fire danger are typically determined by examining the relationship between fire danger indices and fire activity (number of fire starts, size of fires, etc.) (Helfman et al. 1980, Andrews et al. 2003). Due to lack of fire occurrence data, we defined levels of fire danger based solely on fire danger index values, which is not the preferred method of analysis. An older and larger weather data set (Bradshaw) that contained state-of-theweather information was used to predict state-of-the-weather for the smaller data set (RAWS), which did not include state-of-theweather. Data from Bradshaw Army Airfield 
(located in PTA) were collected for the period 1995-1999 predominantly during daylight hours (94\%). The Bradshaw data set comprised 1,094 daily records that contained the observed state-of-the-weather, air temperature, maximum air temperature, relative humidity, and precipitation amount. Stateof-the-weather values range from 0 to 9 (Cohen and Deeming 1985): 0, clear; 1 , scattered clouds; 2 , broken clouds; 3 , overcast; 4 , foggy; 5, drizzling; 6, raining; 7, snow/sleet; 8 , showering; 9, thunderstorms in progress. The U.S. Army established three remote automated weather stations (RAWS) at PTA in August 1999 (Figure 3): PTA East, Kīpuka 'Alalā, and PTA West. At the time of this study (June 2000), each RAWS had approximately 235 daily observations available for use. The RAWS daily weather data consisted of the afternoon (1300 hours) air temperature and relative humidity, daily minimum and maximum air temperature, and precipitation amount. We used classification and regression tree analysis to develop a classification tree and a regression tree to predict state-of-theweather using the Bradshaw observations (Breiman et al. 1984). Both of the resulting trees were applied to the three RAWS data sets to predict state-of-the-weather. A fire danger fuel model was assigned to each RAWS, and fire danger indices were calculated using the FireFamily Plus 2.0 software (Bradshaw and McCormick 2000).

The NFDRS fuel models designated as B, C, D, F, L, O, and T (Deeming et al. 1977) were initially considered to represent the fuels at PTA based on measured fuel loads. Because of the impact of fountain grass on fire occurrence in Hawai' $\mathrm{i}$, fuel model $\mathrm{N}$ was added and fuel model $\mathrm{F}$ was selected to represent the remainder of the vegetation at PTA. In the fire planning process, the statistical distribution of one or more of the NFDRS indices has typically been compiled for a period of $10 \mathrm{yr}$. Helfman et al. (1980) suggested defining the lower index value of each fire risk class based on the percentile values of the index: low (0), moderate (1/4 of 90th percentile value), high (1/2 of 90 th percentile value), very high (90th), and extreme (97th). For a normally distributed index, the lower values of the moderate and high classes would correspond to the 63rd and 74th percentiles, respectively. For this study, the median (50th), 75th, and 95th percentile values of the Burning Index and Spread Component indices were determined for the Bradshaw data. The RAWS data were then searched to identify days that exhibited the index values jointly. The weather and fuel moisture data on those days were used in the fire spread simulations.

\section{Simulation of Fire Risk}

Multiple fire spread simulations were run to estimate fire risk. The FARSITE system is a graphical two-dimensional implementation of the Rothermel fire spread model. Fire spread simulations using FARSITE required air temperature, relative humidity, wind velocity and direction, initial fuel moisture content, and spatial data describing the slope, elevation, aspect, and fuel types at PTA (Finney 1998). Slope, elevation, and aspect were derived from U.S. Geological Survey $30 \mathrm{~m}$ digital elevation models (DEMs). Based on the vegetation and fuel sampling that was performed (Weise and Fujioka 2001, Wright et al. 2002), four of the 13 original fire behavior fuel models (Albini 1976) and eight custom fuel models were assigned by vegetation type to the PTA landscape (Figure 3). Hourly weather observations for the dates selected (see earlier) were used. Initial fuel moisture content scenarios were developed for each date.

One hundred ignition points were randomly located within the boundaries of PTA outside the impact area because human activities that could result in ignition occurred in all areas external to the impact area and the cantonment. Time of ignition was set at 1300 hours local standard time with the assumption that that was typically the time of day when conditions for ignition are optimum. Given that fire danger indices are calculated daily, weather conditions change rapidly, and we had a limited amount of observed hourly weather data, we chose to simulate only $24 \mathrm{hr}$ of fire growth from each ignition point separately. Further simulation 


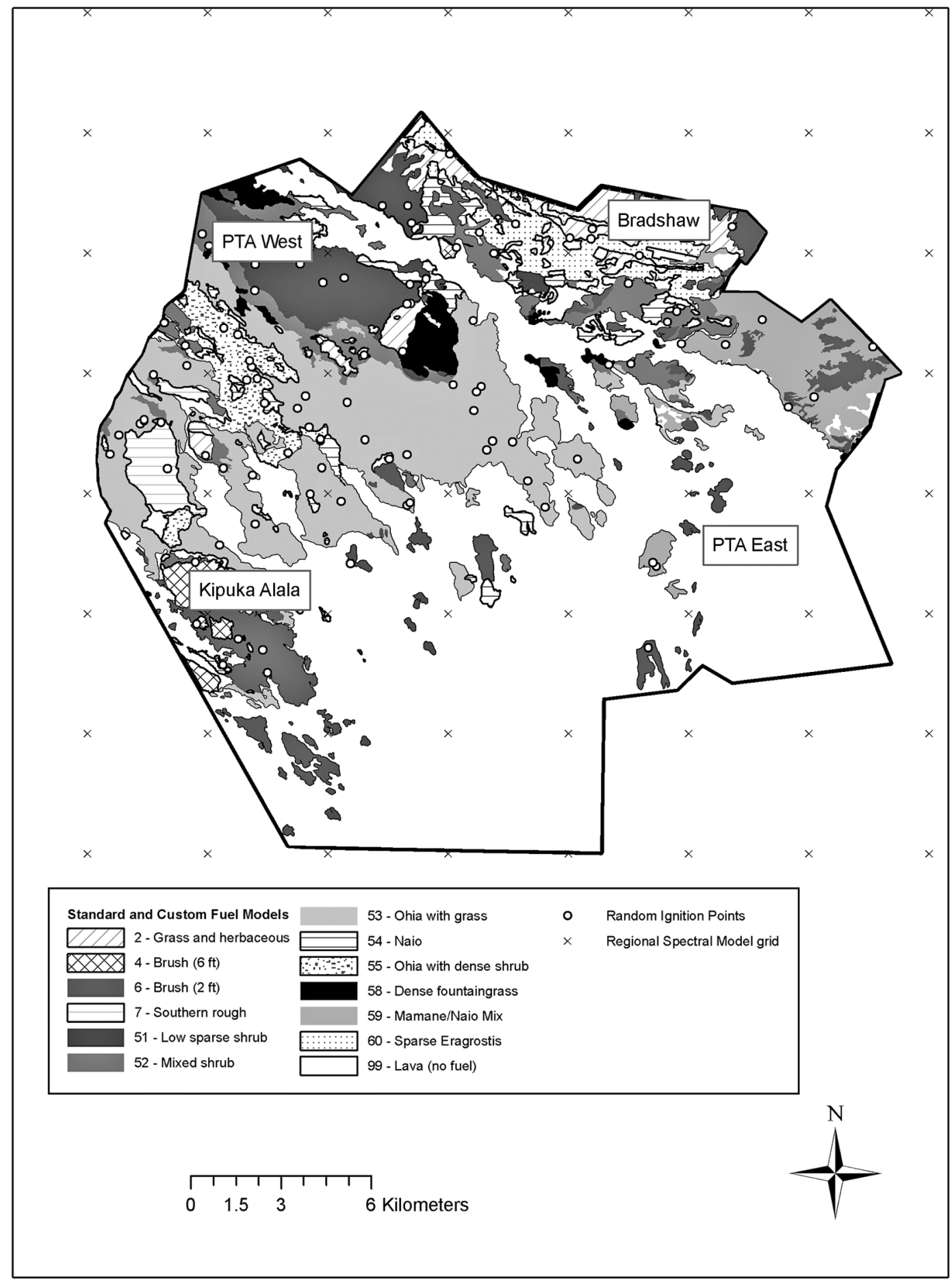

Figure 3. Location of fuel types, weather data, and ignition points for fire risk simulations at Pōhakuloa Training Area, Hawai'i. Fuel models 51-60 are custom models based on fuel sampling. 
details can be found in Moody and Stephens (2000). Finney (2005) presented a simplified version of our approach using FARSITE to simulate fire risk on a $900 \mathrm{~km}^{2}$ area near Missoula, Montana; 20,000 simulations were used in his example with a simplified weather scenario. Roloff et al. (2005) also used FARSITE and other tools to estimate short- and long-term risk associated with fuel treatments in the southern Cascades of Oregon. Sixteen ignition points were used in the Roloff et al. study. At the time the Pōhakuloa study was performed (1999-2000), several personal computers were necessary to complete the fire simulations over a period of several weeks. The Rothermel spread model is integral to the FARSITE and NFDRS systems, so the underlying assumptions made affect the fire spread components of both systems in a similar manner. Because the intent of this study was to estimate fire risk as influenced by weather data types, the accuracy of the Rothermel model in these fuel types was not an issue. There has been a limited amount of work comparing fire spread estimates with actual fire behavior in Hawaiian fuels.

Because PTA is influenced by both windward and leeward weather patterns due to its location, increased resolution in weather data might improve fire risk prediction. Prior work has shown the sensitivity of fire spread simulations using FARSITE to weather data resolution (Weise and Fujioka 1998). The availability of multiple weather stations and high-resolution gridded weather predicted by the Mesoscale Spectral Model (Juang 1992, Wang et al. 1998) afforded us the opportunity to further examine the effect of spatial resolution of weather data on simulated fire size and corresponding risk. The Mesoscale Spectral Model is a "set of fully compressible nonhydrostatic equations governing a broad spectrum of atmospheric motion" (Juang 1992:75). These equations predict various atmospheric properties (temperature, water content, wind velocity, pressure, etc.) on a three-dimensional grid that begins at the earth's surface and extends several kilometers up into the atmosphere. For this study, the
Mesoscale Spectral Model horizontal spacing between grid points was $4 \mathrm{~km}$.

To determine the effect of weather data spatial resolution on simulated fire risk, three sets of weather data were used as input to FARSITE: (1) PTA East RAWS, (2) all three RAWS (PTA, PTA West, and Kīpuka 'Alalā), and (3) Mesoscale Spectral Model-predicted gridded weather data. These weather data sets were labeled PTA East, Three RAWS, and Gridded, respectively, and represented an increasingly finer scale: one "station" per $42,600 \mathrm{ha}\left(426 \mathrm{~km}^{2}\right)$ for PTA East to one "station" per 1,470 ha for the gridded weather data. The surface layer predictions from the Mesoscale Spectral Model were used. The Three RAWS weather set was implemented in version 3 of FARSITE by assigning data from a particular weather station to a portion of the landscape. The eastern half of PTA was assigned to the PTA East RAWS, the southwestern $30 \%$ was assigned to Kīpuka 'Alalā RAWS, and the northwestern 20\% was assigned to the PTA West RAWS. This implementation of FARSITE did not allow for a gradation of weather data between grid cells or weather stations. Thus abrupt changes in weather conditions occur as a fire spreads from the influence of one weather station to the next.

The three fire danger percentiles $(50,75$, 95) were combined with the three resolutions of weather data (PTA East, Three RAWS, Gridded), producing a total of nine weather scenarios that were used for the FARSITE simulations. The nine weather scenarios and the 100 ignition points resulted in a total of 900 fire spread simulations. A predicted area burned for each of the 100 ignition points was output, and the 100 fire areas were overlaid into a single file containing the number of times that each pixel was burned. The number of times burned was chosen as the measure of fire risk. Fire risk as defined in this study was a function of the random placement of ignitions distributed uniformly across the landscape, the fuel and weather conditions, and the spread pattern simulated by FARSITE.

As mentioned earlier, the Ignition Compo- 
nent is a measure of the probability that a fire will successfully ignite and result in a fire requiring suppression. The Ignition Component is a function of the predicted rate of spread and should be partially related to the simulated fire risk. The Ignition Component was calculated for each fuel type and training area by assigning data from the closest RAWS as was done for the fire spread simulations. The Ignition Component was calculated from the predicted weather at each Mesoscale Spectral Model grid point. Because of the limited amount of Mesoscale Spectral Model data, the calculated fuel moistures for $1,10,100$, and $1,000 \mathrm{hr}$ dead, live woody, and live herbaceous fuels calculated by FireFamilyPlus 3.05 using the RAWS data were used to calculate the Ignition Component for the Mesoscale Spectral Model data. The Ignition Component for the Three RAWS weather scenario was calculated as fuel model area weighted averages. Because multiple Mesoscale Spectral Model grid points fell within a fuel type, the unweighted arithmetic mean was calculated for the Ignition Component for each fire danger percentile. Simple correlation coefficients were estimated to examine agreement between fire risk and the Ignition Component.

\section{Effect of Weather Resolution on Fire Risk}

Before examining the effects of weather data resolution on simulated fire risk, we compared observed weather data (RAWS) with predicted weather data (Mesoscale Spectral Model). Correlations between observed and predicted temperature, relative humidity, wind speed and direction were calculated for each weather station and weather percentile. The predicted weather values for the grid point closest to each RAWS were used in the correlation analysis. Because of the $3 \mathrm{hr}$ time increment in the gridded weather data, only eight values were available for analysis for each date. Because of the uncertainty of the distributional properties of the data, both parametric (Pearson's product-moment correlation $\rho$ ) and rank-based (Kendall's $\tau$ and Spearman's $\rho$ ) statistics were calculated for each observed/predicted pair (temperature, relative humidity, wind speed). The significance of these three measures of association was tested. A version of the Pearson correlation coefficient for circular data was calculated and tested for the wind direction data (Jammalamadaka and Sarma 1988).

After comparing the weather data, the influence of weather data resolution on fire risk was examined. Analysis of variance was used to test if the total area burned by fuel type differed between weather percentiles and weather data resolutions. Because the same ignition points were used, pairwise difference in predicted fire size was calculated for each ignition point (PTA EastThree RAWS, PTA East-Gridded) for each weather percentile. Each pairwise difference was coded as 0 or 1 to indicate that the fire size difference was less than or equal to zero or was greater than zero, respectively. The means, medians, and interquartile ranges for the pairwise differences were calculated to determine if fire size differed between the weather sources by weather percentile. The nonparametric Wilcoxon signed-rank statistic and Student's $t$-statistic tested if the median and mean pairwise differences differed from 0 , respectively. The probability level $\alpha=$ 0.05 defined significant test results.

A randomization test was devised to test if like differences tended to be closer spatially (0s closer to 0s, 1s closer to 1s) for each weather percentile and pairwise difference combination (total of six). The null hypothesis was that there was no spatial association between like differences, with the alternative hypothesis that there was some spatial association between like differences. To test this hypothesis, a mean distance ratio was calculated (eq. 1). This test is similar in form to the distance sampling techniques described by Pielou (1977) and Diggle (2003), where $\bar{D}$ is the mean distance ratio, $d_{l}$ is the distance from an ignition point to the closest ignition point with a like difference $(0,1)$, and $d_{u}$ is the distance to the closest unlike difference.

$$
\bar{D}=\frac{\sum_{1}^{100} d_{l} / d_{u}}{100}
$$


The effect of the weather scenarios on fire risk was examined. Spatial analysis was performed to determine if the location of fire risk changed as spatial resolution of weather data changed. Risk was classified into five classes representing low (0 to 4), moderate (5 to 8 ), high (9 to 12 ), very high (13 to 16 ), and extreme (17 to 20). These classes were then converted to polygons and the location of the mean center of the centroids was determined for each class to determine if there was a shift in the centroids for each of the nine weather scenarios.

\section{RESULTS}

\section{Determination of Fire Danger Weather Conditions}

Ninety-one percent of the 1,094 days of Bradshaw weather data were sunny (stateof-the-weather $<3$ ) with the remaining $9 \%$ having some form of precipitation at the observation time. Overall, the regression tree misclassified 230 observations $(21 \%)$, and the classification tree misclassified 73 observations $(7 \%)$. In the NFDRS, if the state-ofthe-weather value is 3 or less, the temperature and relative humidity are adjusted to estimate conditions in the immediate vicinity of a fuel particle, which are then used to calculate equilibrium moisture content (Byram and Jemison 1943, Cohen and Deeming 1985). For state-of-the-weather values between 5 and 7 , which usually result in measurable precipitation, fuel moisture content is set to $35 \%$. In light of these critical adjustments, the misclassification of state-of-the-weather values in these two categories ( 0 to 3,5 to 7 ) was determined. For the sunny days, less than $1 \%$ of the observations were misclassified as days with precipitation. In contrast, nearly half of the 59 "wet" observations were misclassified as sunny days. Misclassification of observations in the 0 to 3 category would potentially result in lower fire danger values because the predicted fuel moistures would be higher than actual. Misclassification of the observations in the 5 to 7 category would result in higher fire danger index values due to lower fuel moistures. Given the high success rate for sunny days, we felt confident applying the classification and regression tree models to the 235 days of RAWS data to estimate state-of-the-weather.

The median, 75 th, and 95th percentile values for fuel model $\mathrm{F}$ were lower than the values for fuel model $\mathrm{N}$ for both indices (Table 1). These indices suggest that expected fire rate of spread and flame length

TABLE 1

Percentile Values for Two NFDRS Indices for Two Different Fuel Models for the Three Sources of Weather Data

\begin{tabular}{|c|c|c|c|c|c|}
\hline \multirow[b]{2}{*}{ Index } & \multirow[b]{2}{*}{ Fuel Model } & \multirow[b]{2}{*}{ Weather Data ${ }^{a}$} & \multicolumn{3}{|c|}{ Percentile } \\
\hline & & & Median & 75 th & 95 th \\
\hline \multirow[t]{6}{*}{ Burning Index (BI) } & \multirow[t]{3}{*}{$\mathrm{F}$} & Bradshaw & 29 & 35 & 48 \\
\hline & & PTA Short & 21 & 25 & 40 \\
\hline & & PTA Long & 18 & 23 & 32 \\
\hline & \multirow[t]{3}{*}{$\mathrm{N}$} & Bradshaw & 76 & 92 & 120 \\
\hline & & PTA Short & 63 & 74 & 96 \\
\hline & & PTA Long & 62 & 76 & 93 \\
\hline \multirow[t]{6}{*}{ Spread Component (SC) } & \multirow[t]{3}{*}{$\mathrm{F}$} & Bradshaw & 10 & 13 & 23 \\
\hline & & PTA Short & 8 & 10 & 16 \\
\hline & & PTA Long & 8 & 11 & 16 \\
\hline & \multirow[t]{3}{*}{$\mathrm{N}$} & Bradshaw & 59 & 85 & 144 \\
\hline & & PTA Short & 47 & 63 & 102 \\
\hline & & PTA Long & 49 & 68 & 98 \\
\hline
\end{tabular}

\footnotetext{
${ }^{a}$ Bradshaw: Bradshaw Army Airfield data for 1995-1999; PTA Short: PTA East, PTA West, PTA Kīpuka 'Alalā RAWS data July 1999 to March 2000; PTA Long: PTA East July 1999-July 2005, PTA West, PTA Kīpuka 'Alalā August 1999-December 2006.
} 
would be greater in the fountain grass areas of PTA. The percentile index values for the same fuel models using the RAWS data (July 1999-March 2000) were generally lower than the values calculated from the Bradshaw weather data due to the shorter period of record. The dates selected from the RAWS data set for FARSITE simulations to represent median, $75 \%$, and $95 \%$ conditions were 8-9 December 1999, 14-15 August 1999, and 19-20 February 2000, respectively. When a longer record period for the RAWS was considered (1999-2006), the percentile values for the dates selected were 74th, 88th, and 95th for fuel model F, respectively, and 70th, 80th, and 99.5th for fuel model N, respectively. The percentile values of both the Burning Index and the Spread Component were consistently lower than in the Bradshaw data set, suggesting that the weather conditions during these two time periods (19951999, 1999-2006) might be different.

The wind direction data indicated that the daytime wind direction differed between the four weather stations for the period JulyNovember 1999. Although this is a short period of overlap, analysis of longer periods indicates that the data are representative. PTA East wind velocities were generally higher and came predominantly from the southeast, whereas the wind velocities for the two western RAWS were lower and primarily from the northwest. Wind direction at Bradshaw Army Airfield was predominantly from the west. Only daytime weather data were available for Bradshaw. In general, the RAWS observations were not well correlated with the predicted weather at the nearest grid point. Only observed temperature was significantly correlated with the Mesoscale Spectral Model-predicted temperature. All three measures of association (Pearson's $\rho$, Kendall's $\tau$, Spearman's $\rho$ ) for all three RAWS were significant. All three measures also indicated that observed and predicted relative humidity were significantly correlated for all three RAWS for only the 75 th percentile weather. All other measures of correlation between observed and predicted values for relative humidity, wind speed, and direction were not significant and generally poor for all RAWS and weather percentiles. Mean observed temperature and mean predicted temperatures were in good agreement-generally within $2{ }^{\circ} \mathrm{C}$; the difference between mean observed and predicted relative humidity ranged from $5 \%$ to $33 \%$ with the greatest differences occurring at the 95 th percentile weather conditions. Of the three weather stations, no single station data appeared to be better correlated with the Mesoscale Spectral Model-predicted data. Predicted relative humidity values for the extreme fire risk scenarios were much greater than observed relative humidity at all three RAWS. The minimum observed relative humidity for the extreme fire risk date was $<10 \%$, which may indicate dry air usually found above the trade wind inversion $(\mathrm{Na}-$ tional Climatic Data Center document at http://www5.ncdc.noaa.gov/climatenormals/ clim60/states/Clim_HI_01.pdf). Rapid drops in relative humidity (from $80 \%$ to $10 \%$ ) in 1 hr were recorded by the RAWS on 14 February 2000. Other very low relative humidity values were recorded between August 1999 and March 2000 by the RAWS. These variations in relative humidity are possible, given that PTA lies in the middle of the elevation band through which the trade wind inversion migrates (1,200-2,400 m). The inversion caps the boundary layer moistened by the Pacific Ocean, creating relative humidity differences upwards of $70 \%$ from one side of the inversion to the other.

\section{Weather Effects on Fire Risk Simulation}

The spatial distribution of simulated ignitions at PTA was random (Figure 3) within the fuel types; much of the landscape is lava and does not contain any combustible fuel. The distribution of number of ignition points by fuel type was similar to the proportional distribution of fuel types, confirming the uniform probability of location for an ignition point. 'Ōhi'a (Metrosideros polymorpha) with grass was the dominant fuel type at PTA and occupied over 6,400 ha of the 20,385 ha with sufficient vegetation cover to be considered a fuel type. Nearly one-third of the ignition points were located in this fuel type. It was observed during the Three RAWS 
TABLE 2

Differences in Simulated Fire Size for 100 Random Ignition Points for Different Weather Scenarios, Pōhakuloa Training Area, Hawai'i

\begin{tabular}{llcccc}
\hline \hline \multirow{2}{*}{$\begin{array}{l}\text { Weather } \\
\text { Percentile }\end{array}$} & \multicolumn{1}{c}{ Type } & Median & Range $^{a}$ & Mean & Std. Error \\
\cline { 2 - 5 } & PTA East-Three RAWS & $-467 .^{*}$ & 1,036 & $-328^{*}$ & 71 \\
50 & PTA East-Gridded & $-87 .^{*}$ & 396 & $-226^{*}$ & 40 \\
50 & Three RAWS-Gridded & 239. & 1,156 & 102 & 89 \\
75 & PTA East-Three RAWS & 0. & 908 & 117 & 72 \\
75 & PTA East-Gridded & -15. & 239 & -5 & 22 \\
75 & Three RAWS-Gridded & -1. & 732 & $-123^{*}$ & 61 \\
95 & PTA East-Three RAWS & 0. & 721 & 93 & 81 \\
95 & PTA East-Gridded & -107. & 738 & -18 & 89 \\
95 & Three RAWS-Gridded & $-29^{*}$ & 345 & $-111^{*}$ & 55 \\
\hline
\end{tabular}

${ }^{a}$ Interquartile range.

* Difference is significantly different from 0 .

simulations that fires spreading across weather boundaries sometimes changed appreciably when crossing the boundary. Specifically, fires that spread in an easterly direction sometimes stopped upon encountering the boundary between the PTA East RAWS and the PTA West RAWS. Due to the influence of trade winds, the PTA East RAWS had higher relative humidity and cooler temperatures than the PTA West RAWS, resulting in higher fuel moistures and reduced fire spread. As previously noted, the daytime wind direction differed between the eastern and western portions of PTA as well. This boundary effect was not observed when the Gridded data were used because the changes in weather variables from east to west were smoother.

The mean Three RAWS and Gridded fire sizes were significantly larger than the PTA East fire sizes by 328 and 226 ha, respectively, for the 50th percentile weather (Table 2). Mean fire sizes at the 75th and 95th percentiles for the Gridded data were significantly larger than the mean fire sizes for the Three RAWS data. Median differences in fire size between PTA East and the other two data sets were significantly different from 0 for the 50th percentile weather. The median fire size difference between Three RAWS and Gridded was also significantly different than 0 for the 95 th percentile weather. The interquartile ranges indicated that the scale of the difference data was quite different among the nine weather scenarios (Table 2). The smallest interquartile range was 239 and the largest was 1,156 . No consistent trend in the size of the interquartile range was observed; however, two of the three smallest ranges occurred in the differences between the PTA East and Gridded fire sizes for the 50th and 75 th percentile weather.

Results of the analysis of variance indicated that the weather percentile affected the mean area burned in the 'Öhi'a with Grass, 'Ōhi'a with Dense Shrub, and Sparse Eragrostis fuel types. These three fuel types represent $43 \%$ of the landscape with sufficient fuel to support fire spread. The weather data type significantly affected mean area burned in the intermediate 'Ōhi'a mixed treeland vegetation type (Shaw and Castillo 1997), which was modeled using the NFFL fuel model 7. Dodonaea viscosa, Osteomeles anthyllidifolia, and Styphelia tameiameiae were the dominant shrubs in this type; fountain grass was invading this community in 1997. The experimental setup did not allow a statistical test of the effects of interaction between weather percentile and weather data source on area burned by fuel type. Graphically, it can be seen that the effects were mixed (Figure 4). For the PTA East weather data, the area burned increased with weather percentile in all fuel models. The 75 th percentile 


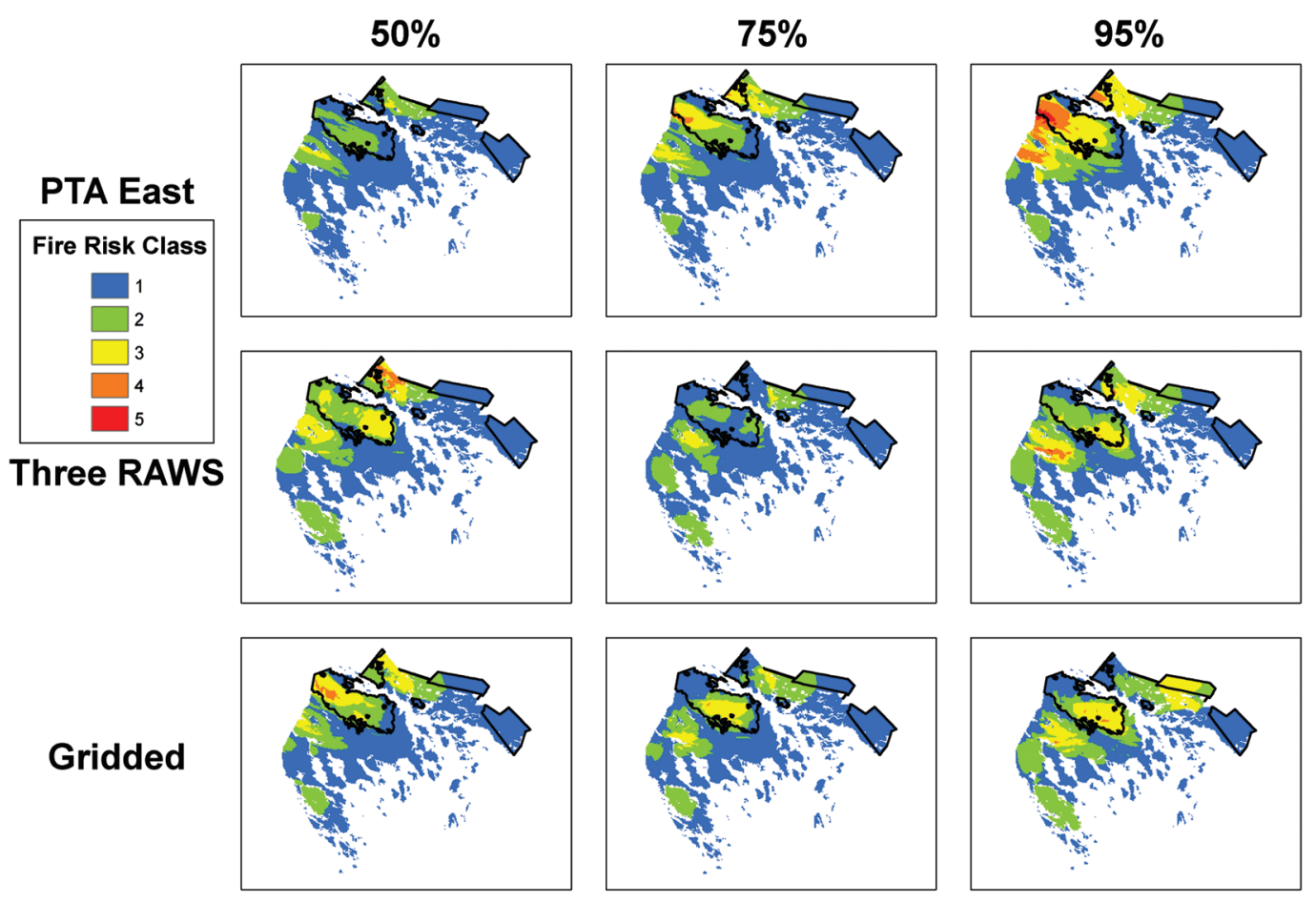

Plate I. Spatial distribution of fire risk for nine simulated weather scenarios, Pōhakuloa Training Area (PTA), Hawai'i. Simulated fire risk was generally greater in the northwestern portion of PTA and associated with the Kipuka Kālawamauna Endangered Plant Habitat Area and Palila Critical Habitat.
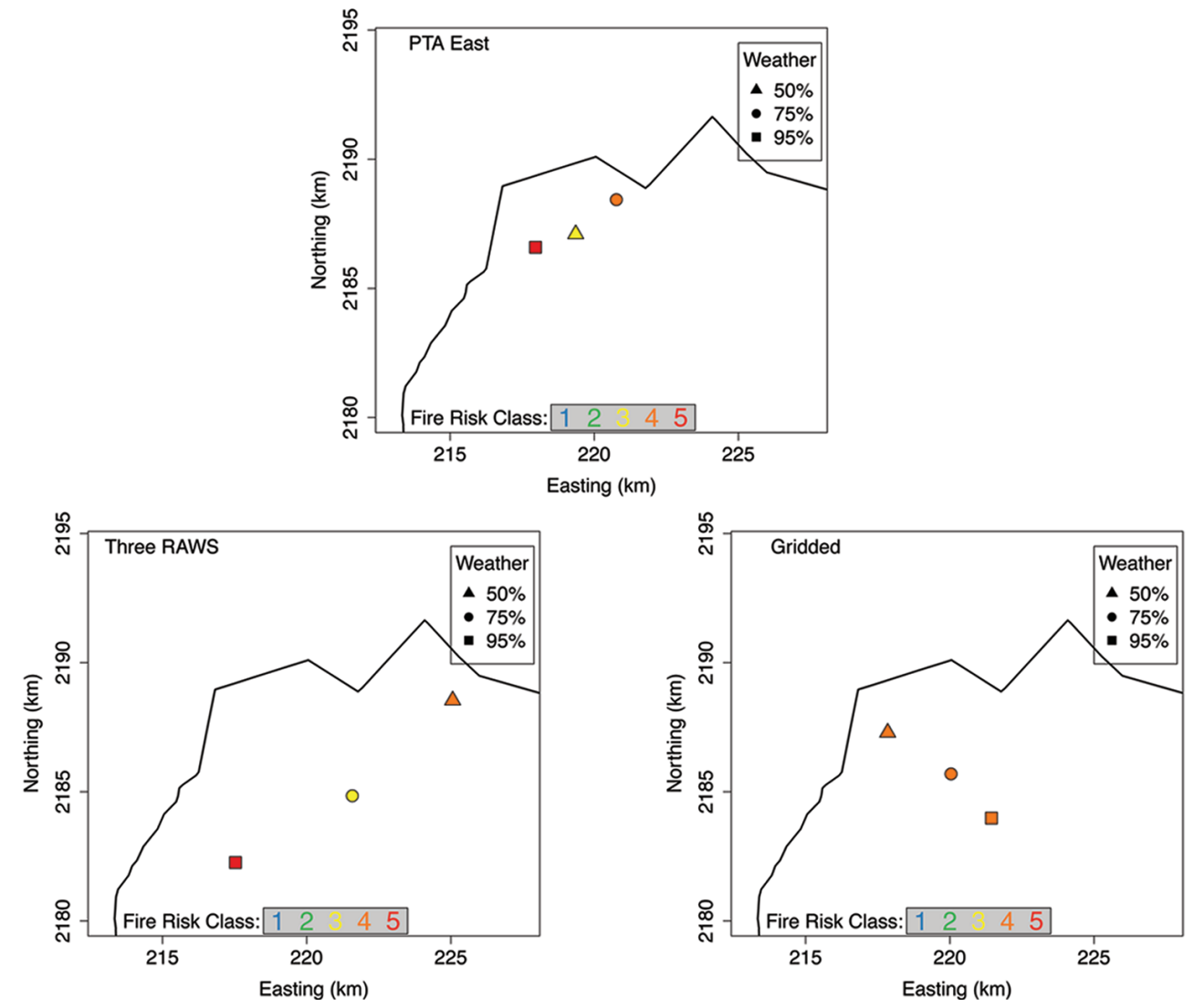

PLATE I I. Location of fire risk centroids as affected by weather percentile for three weather data resolutions, Pōhakuloa Training Area, Hawai ‘i, UTM zone 5 N. Symbol shape determines weather percentile; symbol color identifies fire risk value. Only PTA East (single station) simulations exhibited positive correlation between fire risk class and weather percentile. 
PTA East
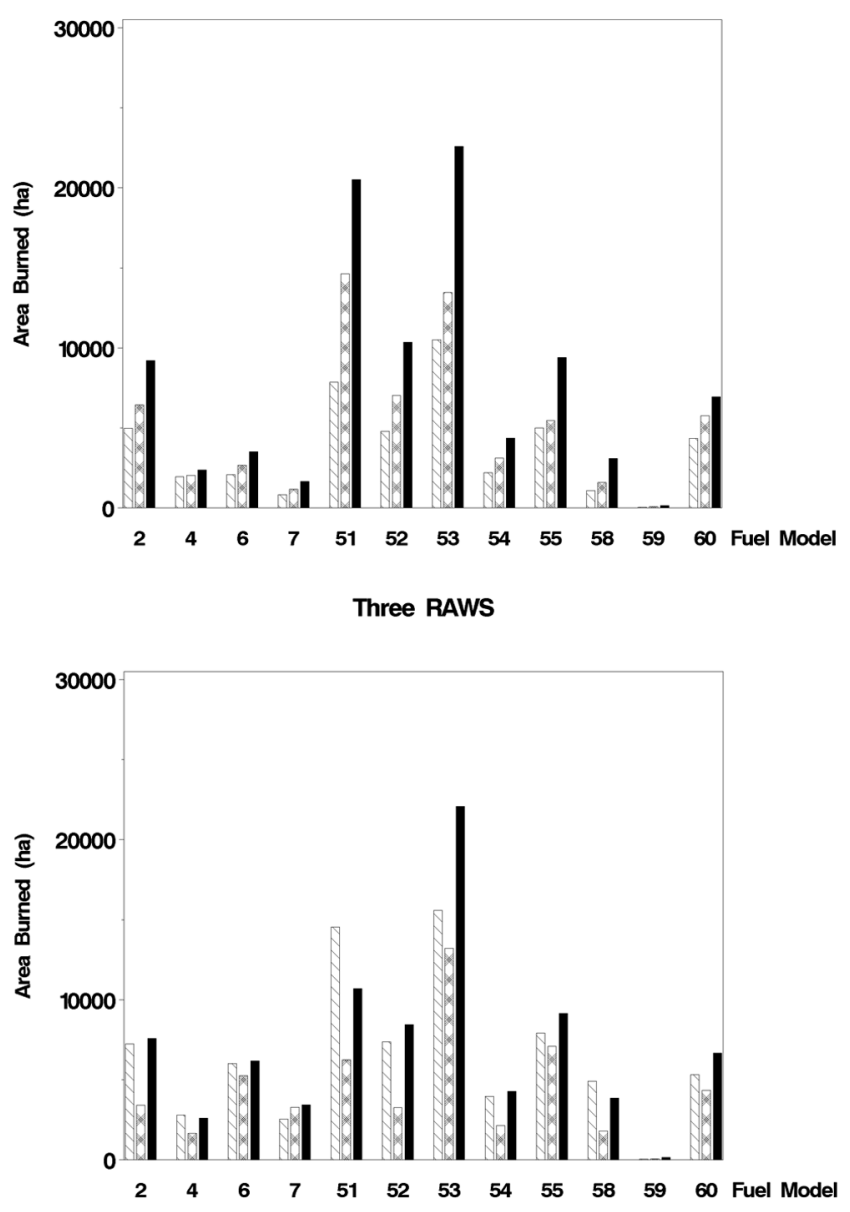

Gridded

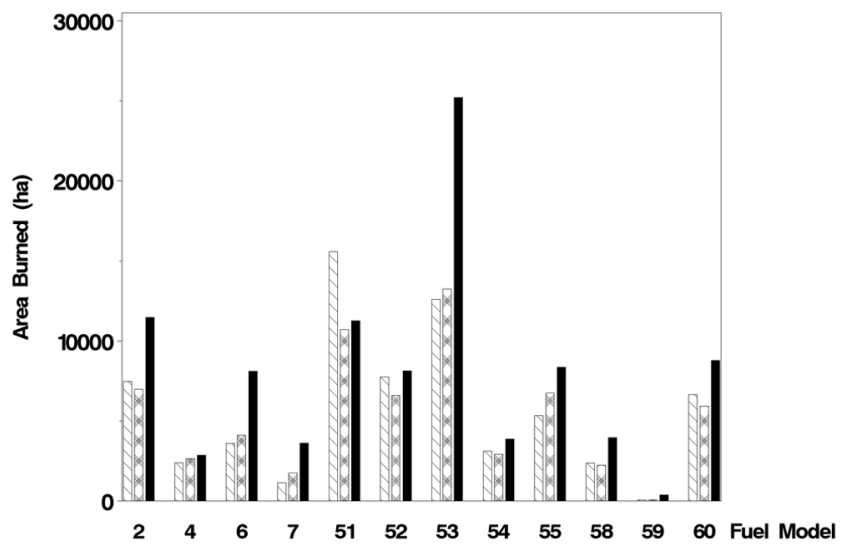

Figure 4. Total area burned for nine simulated weather scenarios (three weather percentiles $\times$ three weather data sources), Pōhakuloa Training Area, Hawaii. Within a fuel model, the weather percentiles from left to right are 50th, 75 th, and 95 th. Fuel model numbers are defined in Figure 3. Only PTA East simulations consistently resulted in positive correlation between area burned and weather percentile for all fuel models. 
TABLE 3

Randomization Test Results for Spatial Association in Coded Values of Pairwise Difference in Predicted Fire Size for Various Weather Scenarios, Pōhakuloa Training Area, Hawai'i (Like Pairwise Differences Tended to Be Closer

Together [Observed Ratio Less than the Lower 0.05 Proportion of the Empirical Distribution Function])

\begin{tabular}{|c|c|c|c|c|c|c|c|}
\hline \multirow{2}{*}{$\begin{array}{l}\text { Weather } \\
\text { Percentile }\end{array}$} & \multirow[b]{2}{*}{ Difference Type } & \multirow[b]{2}{*}{ Observed Ratio $^{a}$} & \multicolumn{5}{|c|}{ Empirical Distribution $^{b}$} \\
\hline & & & 0.001 & 0.01 & 0.05 & 0.50 & Mean \\
\hline 50 & PTA East-Three RAWS & 1.084 & 0.944 & 1.138 & 1.321 & 1.914 & 1.946 \\
\hline 50 & PTA East-Gridded & 0.905 & 0.770 & 0.878 & 1.016 & 1.615 & 1.692 \\
\hline 75 & PTA East-Three RAWS & 0.968 & 1.027 & 1.165 & 1.373 & 1.985 & 2.008 \\
\hline 75 & PTA East-Gridded & 1.097 & 1.053 & 1.158 & 1.381 & 1.991 & 2.002 \\
\hline 95 & PTA East-Three RAWS & 0.983 & 1.048 & 1.223 & 1.382 & 1.980 & 1.986 \\
\hline 95 & PTA East-Gridded & 1.045 & 1.102 & 1.185 & 1.373 & 1.981 & 1.988 \\
\hline
\end{tabular}

${ }^{a}$ Mean distance ratio $\bar{D}=\frac{\sum_{1}^{100} d_{l} / d_{u}}{100}$

${ }^{b}$ Lower tail values of empirical distribution function of distance ratio statistic derived by performing randomization test with 1,000 permutations of observed difference types $(0,1)$. Total number of possible permutations of the observed difference set is 100 ! or approximately $9.33 \times 10^{157}$.

simulations burned the least area for all fuel models for the Three RAWS weather data. In the Gridded simulations, area burned increased with weather percentile for half of the fuel models; the 75 th percentile simulations were the smallest for the other half of the fuel models.

The Anderson-Darling and Cramer-von Mises tests indicated that the test statistic devised to test if like differences in predicted fire size were clumped was generally not normally distributed (Stephens 1986). The observed mean distance ratios $(\bar{D})$ fell in the range of 0.9 to 1.1 (Table 3 ). For all six pairwise differences, the observed distance ratio was smaller than the lower $5 \%$ value of the edf, and five of six differences were smaller than the lower $1 \%$ value. Mean and median values of the distance ratio edf ranged from 1.6 to 2.0. Results of the randomization test suggest that there was some spatial association (clumping) between like-signed $(+,-)$ differences. In other words, if the pairwise difference between predicted fire sizes was greater than zero, there was a better than $50 \%$ chance that the pairwise differences at ignition points close by were also greater than zero.

Nine maps of fire risk were produced: one per weather scenario. With 100 fire simulations, the individual fire perimeters can be seen in a composite figure of all simulations
(Figure 5). Observe that the simulated fire shapes were generally elliptical in nature, which is the assumed shape for a fire spreading under uniform conditions without suppression (Anderson 1983). Longer simulation periods would have resulted in fire perimeters that differed from elliptical as weather, fuel, and topography changed. Fire risk ranged from 1 to 20 , indicating that a particular pixel was burned 20 times in at least one of the nine scenarios (Plate I). As the weather percentile increased, the number of times that a pixel was burned increased for PTA East (Table 4). Pearson's correlation coefficient $(r=0.996, n=3, \alpha=.0537)$ and Spearman's correlation coefficient $(\rho=1.0, n=3, \alpha<$ $.0001)$ indicated significant agreement between fire risk and the Ignition Component for the PTA East scenario. Correlation coefficients were not significant for the Three RAWS and Gridded scenarios.

As might be expected, fire risk at PTA is limited to the vegetated areas that tend to be on the western and northern portions of the installation (Plate I). With 100 random ignitions and $24 \mathrm{hr}$ of fire spread simulation, nearly all of the vegetated areas were burned; however, there were differences between the weather types and the risk levels. The increase in fire risk as weather conditions became more extreme for the PTA East scenarios can be seen easily. The higher risk 


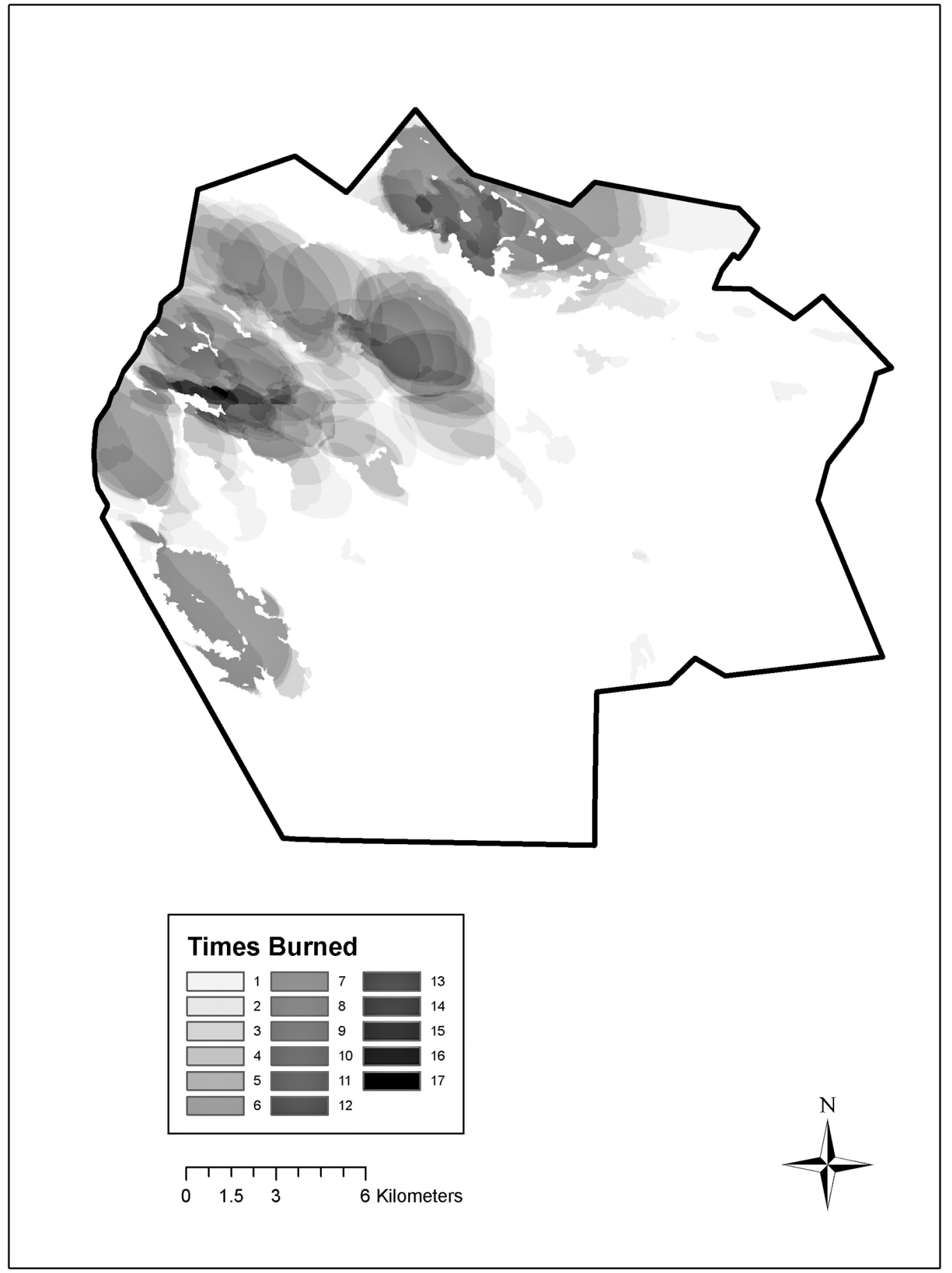

Figure 5. Example map showing spatial distribution of simulated relative fire risk, Pōhakuloa Training Area, Hawai ${ }^{i}$. Perimeters of the individual fires can be seen in this figure. 
TABLE 4

Mean Fire Risk Estimated Using Monte Carlo Simulation and Mean Ignition Component, Pōhakuloa Training Area, Hawai'i

\begin{tabular}{|c|c|c|c|c|c|c|}
\hline \multirow{3}{*}{$\begin{array}{l}\text { Weather } \\
\text { Percentile }\end{array}$} & \multicolumn{6}{|c|}{ Weather Data } \\
\hline & \multicolumn{2}{|c|}{ PTA East } & \multicolumn{2}{|c|}{ Three RAWS } & \multicolumn{2}{|c|}{ Gridded } \\
\hline & $3.6^{a}$ & $11.3^{b}$ & 5.4 & 25.2 & 4.8 & 26.7 \\
\hline 75 & 4.7 & 30.9 & 3.7 & 25.4 & 4.4 & 30.7 \\
\hline 95 & 6.4 & 73.0 & \multirow{2}{*}{\multicolumn{2}{|c|}{0.53}} & 5.8 & 56.8 \\
\hline Pearson's $\rho$ & \multicolumn{2}{|c|}{0.99} & & & \multicolumn{2}{|c|}{0.92} \\
\hline
\end{tabular}

Note: Only PTA East (single weather station) simulations illustrated positive correlation between mean fire risk and weather percentile. See Plate II for related results.

${ }^{a}$ Mean number of times a pixel was burned based on 100 fire spread simulations. Unburned pixels (0) not included in calculation of mean.

${ }^{b}$ Weighted mean Ignition Component. Ignition Component calculated at $1300 \mathrm{hrs}$ on day of ignition for every pixel based on NFDRS fuel type. Mean Ignition Component not weighted for Gridded weather scenarios.

areas increased in size as weather became more extreme for both the Three RAWS and Gridded weather scenarios even though the two sets of scenarios did not differ greatly. The increase in size of the risk areas is a result of the individual fires increasing in size as weather became more favorable for fire spread.

The centroids for the maximum classes of fire risk were calculated for the nine scenarios (Plate II). A centroid can be thought of as the "center of gravity" for the polygon shape representing fire risk. Calculation of centroids was done to determine if there was a shift in location of fire risk as the resolution of the weather data increased from a single station to the gridded weather data. For the PTA East scenarios, the location of the centroid of high fire risk did not change appreciably as the percentile weather increased from $50 \%$ to $95 \%$. There was no progressive change in location. The centroid location initially moved to the northeast $1.9 \mathrm{~km}$ and then moved to the southwest $3.4 \mathrm{~km}$. In contrast, both the Three RAWS and Gridded scenarios showed a progressive change in location of the high fire risk centroid. For the Three RAWS scenarios, the centroid of high fire risk moved progressively from the northeast toward the southwest as weather became more extreme, indicating that more pixels burned in this area of PTA as conditions became drier. The distance between the mean centers for the 50th and 95th percentiles was $9.8 \mathrm{~km}$. For the Gridded scenarios, the high fire risk centroid moved from the northwest to the southeast a distance of $4.9 \mathrm{~km}$. Although the movement of the centroid for the PTA East scenarios might be viewed as insignificant, the movement from the 75 th to 95th percentile center was consistent with the movement direction for the Three RAWS scenarios.

\section{DISCUSSION}

In 2002, the U.S. Army prepared a fire management plan for PTA and other training areas in Hawai'i (U.S. Army 2003). The fire danger and fuels analyses partially presented here and reported elsewhere (Weise and $\mathrm{Fu}-$ jioka 2001, 2003) were incorporated into the fire management plan. Due to the different weather patterns influencing the eastern and western portions of PTA, Weise and Fujioka (2003) recommended that the three RAWS units be maintained to measure the range of weather conditions at PTA and that forecasts produced at Bradshaw Army Airfield be used to anticipate trends in wind, precipitation, and relative humidity. Because of the spatial differences in fire risk that resulted from the simulations due to the resolution of weather and fuels data, we felt that a relatively finegrained approach to fire danger was necessary for PTA. As a result, four NFDRS fuel mod- 
els and their corresponding percentile Burning Index values for low, moderate, high, very high, and extreme fire danger conditions were recommended to represent the variety of vegetation found at PTA. The resulting index values were based on the $4 \mathrm{yr}$ of weather data from Bradshaw and $3 \mathrm{yr}$ from the RAWS (1999-2002).

The similarity of the Three RAWS and Gridded scenarios at the 95th percentile is important to note. These scenarios were produced from wind data that accounted for the differences between the eastern and western portions of PTA. The Gridded scenario represented risk based on weather model predictions, and the Three RAWS scenario represented risk based on observed weather at a few points. Both scenarios predicted moderate to high fire risk in or near the Palila Critical Habitat area on the northern edge of PTA and in the eastern portion of the Kipuka Kālawamauna (Plate I). The similarity between the Three RAWS fire risk and the Gridded fire risk is important for two reasons. First, both sets of data provided improved spatial resolution of the range of weather conditions that occurred at Pōhakuloa at given times in contrast to a single weather station. Fire risk was determined for each landscape cell that was $900 \mathrm{~m}^{2}$ in size. Although this level of resolution is far below the broad geographic area that the NFDRS was originally designed for, the biological resources at risk from wildfire damage at Pōhakuloa are mapped to this resolution. Thus fire danger was described at an improved spatial resolution enabling the possibility of improved fire danger-related decisions. Second, because the weather-modeled risk was similar to the observed weather risk, the possibility to make earlier decisions based on forecast highresolution fire risk based on weather model forecasts exists. However, further validation of the modeled weather is necessary.

Fire hazard is a function of fuels, weather, topography, and ignition probability. The relationships between these variables and the effects on hazard are complex. The fact that fire risk increased as the weather percentile increased for the single weather station (PTA East) scenario only illustrates this com- plexity. In this study, fire risk was generally lowest for the 75 th percentile weather. Due to the difference in weather between the eastern and western portions of PTA, the actual weather percentile values for the individual weather stations for a given time will likely be quite different. These differences in weather will definitely affect the spread of a fire and estimated fire risk. Vegetation types changed over very short distances, which affects potential fire behavior. This complexity has long been recognized, but the approach currently used in the NFDRS is to reduce the complexity in fuel types and select the fuel type of concern for a given area. Simulation modeling in which thousands of fire simulations are run, as in the FSPro model of the Wildland Fire Decision Support System, does not require the reduction of the complexity in fuels and weather that are typically present in landscapes. This complexity is particularly present on Pacific islands, where soil, water, topographic, and temperature gradients result in a great diversity of vegetation types within short distances. We attribute the poor correlation between simulated fire risk and the Ignition Component to the differences between the simulation approach used here and the assumptions underlying use of the NFDRS.

Based on the 100 fire simulations only, the western portion (including Kīpuka 'Alalā, Kīpuka Kālawamauna, and the northwestern portion of the installation at the base of Mauna Kea) burned at a greater frequency than other portions of the installation under the three weather scenarios. This can be interpreted to mean that fire risk (as we have defined it) is greater in those areas. The results of this analysis will most likely be different if different assumptions are used. Proximity to roads is also a known factor influencing fire location; however, public travel along the northern perimeter of PTA is relatively light, and no information on those types of ignitions was available. We assumed a uniform (or equal) chance of ignition throughout all vegetated areas of PTA because we had no prior information to determine ignition locations. This may be an unrealistic assumption because different types of training have different probabilities of fire 
ignition associated with them (e.g., maneuvers versus live fire). Different munitions also have different ignition probabilities associated with them, which could be incorporated into future simulations if the various probability distributions are known. The risk posed by fires originating outside of PTA was not included in this analysis. This risk is important because at least four fires originating to the west and downslope of PTA have either threatened or burned portions of western PTA since the early 1990s. However, with the coarse-scale vegetation map and fuels maps produced by this study, a similar simulation study could be performed to determine fire risk at PTA posed by offinstallation fires.

At the time of this study, the area at PTA occupied by fountain grass was relatively small compared with other vegetation types. Fire simulations spread readily through the other fuel types. As a result of the September 1996 to August 1998 El Niño-Southern Oscillation (ENSO) event, Hawai'i experienced a long drought during half the time period that data were available for Bradshaw Army Airfield (Chu 1989). This drought skewed the weather data toward drier conditions. Simulations based on these fire danger conditions would tend to produce larger fires in a variety of vegetation types than would be expected during moister conditions. Although the risk may be lower in areas with woody vegetation during moister conditions, the external hazard presented by fountain grass still exists. Castillo et al. (2007) reported that fire would spread successfully with wind in living fountain grass with moisture content greater than $270 \%$. The fire spread rates and flame lengths reported by Castillo et al. could be easily suppressed, but the presence of fountain grass poses a hazard that is constantly present. Fire behavior in tropical grasses, many of which are nonnative invasive species, can present a substantial risk and be difficult to suppress due to long flame lengths and high fire intensities (Josiah 1981, Rossiter et al. 2003). Even prescribed burns in tropical grass fuels can exhibit energetic fire behavior due to the relatively deep beds of readilyignited fuel.
Fire danger is a function of climate, fuels, and ignition probabilities. In the relatively short time period encompassed by this study (1995-2002), the weather conditions changed markedly at PTA because of ENSO. Because weather varies on several time scales and vegetation types can change, periodic reanalysis of fire occurrence and associated fire danger indices is encouraged. Fire occurrence and fire danger data are reanalyzed every $10 \mathrm{yr}$ in many national forests in the United States. Although the index values currently in use at PTA were derived under two different periods of weather and may be more moderate in comparison with the index values derived during the ENSO event in the late 1990s, it may be time to consider reanalysis of the data to fine-tune index values to more effectively meet the multiple uses that are expected for PTA.

\section{ACKNOWLEDGMENTS}

We appreciate the logistical support and funding provided by the U.S. Army Garrison-Hawai'i, Schofield Barracks, that enabled the conduct of this study.

\section{Literature Cited}

Ager, A. A., M. A. Finney, B. K. Kerns, and H. Maffei. 2007. Modeling wildfire risk to northern spotted owl (Strix occidentalis caurina) habitat in central Oregon, USA. For. Ecol. Manage. 246:45-56.

Albini, F. A. 1976. Computer-based models of wildland fire behavior: A users' manual. USDA Forest Service Intermountain Forest and Range Experiment Station, Ogden, Utah. Available at http://www.firemodels .org/downloads/behaveplus/publications/ Albini_FIREMOD_1976.pdf

Anderson, H. E. 1983. Predicting winddriven wild land fire size and shape. U.S. For. Serv. Res. Pap. INT-305.

Andrews, P. L., D. O. Loftsgaarden, and L. S. Bradshaw. 2003. Evaluation of fire danger rating indexes using logistic regression and percentile analysis. Int. J. Wildland Fire 12:213-226.

Beavers, A. M., and R. E. Burgan. 2002. Anal- 
ysis of fire history and management concerns at Pohakuloa Training Area. TPS 02-02, Center for the Ecological Management of Military Lands, Colorado State University, Fort Collins.

Blackmore, M., and P. M. Vitousek. 2000. Cattle grazing, forest loss, and fuel loading in a dry forest ecosystem at $\mathrm{Pu}^{6} \mathrm{u} \mathrm{Wa}^{\mathrm{a}} \mathrm{a}^{-}$ Wa'a Ranch, Hawai'i. Biotropica 32:625632.

Bradshaw, L., and E. McCormick. 2000. FireFamily Plus user's guide, version 2.0. U.S. For. Serv. Gen. Tech. Rep. RMRSGTR-67WWW.

Breiman, L., J. H. Friedman, R. Olshen, and C. J. Stone. 1984. Classification and regression trees. Wadsworth International Group, Belmont, California.

Burgan, R. E. 1976. Correlation of plant moisture in Hawaii with the KeetchByram drought index. U.S. For. Serv. Res. Note PSW-307.

- 1987. Concepts and interpreted examples in advanced fuel modeling. U.S. For. Serv. Gen. Tech. Rep. INT-238.

Burgan, R. E., F. M. Fujioka, and G. H. Hirata. 1974. A fire danger rating system for Hawaii. Fire Technol. 10:275-281.

Byram, G. M. 1959. Combustion of forest fuels. Pages 61-89 in K. P. Davis. Forest fire: Control and use. McGraw-Hill, New York.

Byram, G. M., and G. M. Jemison. 1943. Solar radiation and forest fuel moisture. J. Agric. Res. 67:149-176.

Carmel, Y., S. Paz, F. Jahashan, and M. Shoshany. 2009. Assessing fire risk using Monte Carlo simulations of fire spread. For. Ecol. Manage. 257:370-377.

Cary, G. J., R. E. Keane, R. H. Gardner, S. Lavorel, M. D. Flannigan, I. D. Davies, C. Li, J. M. Lenihan, T. S. Rupp, and F. Mouillot. 2006. Comparison of the sensitivity of landscape-fire-succession models to variation in terrain, fuel pattern, climate and weather. Landscape Ecol. 21:121-137.

Castillo, J. M., G. Enriques, M. Nakahara, D. Weise, L. Ford, R. Moraga, and R. Vihnanek. 2007. Effects of cattle grazing, glyphosate, and prescribed burning on fountaingrass fuel loading in Hawai'i.
Pages 230-239 in R. E. Masters and K. E. M. Galley, eds. 23rd Tall Timbers Fire Ecology Conference: Fire in grassland and shrubland ecosystems. Tall Timbers Research Station, Tallahassee, Florida.

Chu, P. S. 1989. Hawaiian drought and the Southern Oscillation. Int. J. Climatol. 9:619-631.

Cohen, J. D., and B. Bradshaw. 1986. Fire behavior modeling: A decision tool. Pages 1-5 in A. L. Koonce, ed. Prescribed burning in the Midwest: State-of-the-art. Proceedings of a symposium, University of Wisconsin, Stevens Point, 3-6 March 1986. Fire Science Center, College of Natural Resources, University of Wisconsin, Stevens Point.

Cohen, J. D., and J. E. Deeming. 1985. The National Fire Danger Rating System: Basic equations. U.S. For. Serv. Gen. Tech. Rep. PSW-82.

Cuddihy, L. W., and C. P. Stone. 1990. Alteration of the native Hawaiian vegetation: Effects of humans, their activities and introductions. University of Hawai'i Press, Honolulu.

D'Antonio, C. M., and P. M. Vitousek. 1992. Biological invasions, the grass fire cycle and global change. Annu. Rev. Ecol. Syst. 23:63-87.

Deeming, J. E., R. E. Burgan, and J. D. Cohen. 1977. The National Fire-Danger Rating System: 1978. U.S. For. Serv. Gen. Tech. Rep. INT-39.

Deeming, J. E., J. W. Lancaster, M. A. Fosberg, R. W. Furman, and M. J. Schroeder. 1972. National Fire-Danger Rating System. U.S. For. Serv. Res. Pap. RM-84.

Diggle, P. J. 2003. Statistical analysis of spatial point patterns. 2nd ed. Arnold, London.

Dolling, K., P. S. Chu, and F. Fujioka. 2005. A climatological study of the Keetch/ Byram drought index and fire activity in the Hawaiian Islands. Agric. For. Meteorol. 133:17-27.

Elmore, A. J., G. P. Asner, and R. F. Hughes. 2005. Satellite monitoring of vegetation phenology and fire fuel conditions in $\mathrm{Ha}-$ waiian drylands. Earth Interact. 9 (21): 121. 
Farris, C. A., C. Pezeshki, and L. F. Neuenschwander. 2000. A comparison of fire probability maps derived from GIS modeling and direct simulation techniques. Pages 131-138 in Joint Fire Science Conference and Workshop, 21-25 June 1999, Boise, Idaho. Vol. 2. University of Idaho, International Association of Wildland Fire, Moscow.

Finklin, A. I., and W. C. Fischer. 1990. Weather station handbook: An interagency guide for wildland managers. National Wildfire Coordinating Group Publication NFES No. 2140. Boise, Idaho.

Finney, M. A. 1998. FARSITE: Fire Area Simulator: Model development and evaluation. U.S. For. Serv. Res. Pap. RMRSRP-4.

. 2005. The challenge of quantitative risk analysis for wildland fire. For. Ecol. Manage. 211:97-108.

Fosberg, M., W. Cramer, V. Brovkin, R. Fleming, R. Gardner, M. Gill, J. Goldammer, R. Keane, P. Koehler, J. Lenihan, R. Neilson, S. Sitch, K. Thornicke, S. Venevski, M. Weber, and U. Wittenberg. 1999. Strategy for a fire module in dynamic global vegetation models. Int. J. Wildland Fire 9:79-84.

Freifelder, R. R., P. M. Vitousek, and C. M. D'Antonio. 1998. Microclimate change and effect on fire following forest-grass conversion in seasonally dry tropical woodland. Biotropica 30:286-297.

Fujioka, F. M., D. R. Weise, and R. E. Burgan. 2000. A high resolution fire danger rating system for Hawaii. Pages 103-106 in Proceedings, 3rd Symposium on Fire and Forest Meteorology, January 2000, Long Beach, California. American Meteorological Society, Boston, Massachusetts.

Giambelluca, T. W., and T. A. Schroeder. 1998. Climate. Pages 49-59 in S. P. Juvik and J. O. Juvik, eds. Atlas of Hawai'i. 3rd ed. University of Hawai'i Press, Honolulu.

Hawai'i Department of Land and Natural Resources. 2007. Fire data. http://www .state.hi.us/dlnr/dofaw/fmp/firedata.htm (last accessed 15 September 2008).

Helfman, R. S., R. J. Straub, and J. E. Deeming. 1980. User's guide to AFFIRMS:
Time-share computerized processing for fire danger rating. U.S. For. Serv. Gen. Tech. Rep. INT-82.

Jammalamadaka, S. R., and Y. R. Sarma. 1988. A correlation coefficient for angular variables. Pages 349-364 in K. Matusita, ed. Statistical theory and data analysis II, Proc. 2nd Pacific Area Statistical Conference, 1986, Tokyo, Japan. North-Holland Publishing Co., Amsterdam.

Josiah, S. J. 1981. Wildland fire on Guam. Fire Manage. Notes 43:3-6. (http://www .fs.fed.us/fire/fmt/fmt_pdfs/043_01.pdf).

Juang, H.-M. H. 1992. A spectral fully compressible nonhydrostatic mesoscale model in hydrostatic sigma coordinates: Formulation and preliminary results. Meteorol. Atmos. Phys. 50:75-88.

Juvik, J. O., D. C. Singleton, and G. G. Clarke. 1978. Climate and water balance on the island of Hawaii. Pages 129-139 in J. Miller, ed. Mauna Loa Observatory: A 20th anniversary report. NOAA Special Report, U.S. Dep. Commerce, National Oceanographic and Atmospheric Administration, Environmental Research Laboratories. (http://www.mlo.noaa.gov/ visitingandtours/pdf/maunaloa20thanniversary/ maunaloa20th1-50zip7.0later.pdf).

Keane, R. E., G. J. Cary, I. D. Davies, M. D. Flannigan, R. H. Gardner, S. Lavorel, J. M. Lenihan, C. Li, and T. S. Rupp. 2004. A classification of landscape fire succession models: Spatial simulations of fire and vegetation dynamics. For. Ecol. Manage. 179:3-27.

Keane, R. E., G. J. Cary, and R. Parsons. 2003. Using simulation to evaluate fire regimes: An evaluation of approaches, strategies, and limitations. Int. J. Wildland Fire 12:309-322.

Keetch, J. J., and G. M. Byram. 1968. A drought index for forest fire control. U.S. For. Serv. Res. Pap. SE-38.

LaCroix, J. J., S.-R. Ryu, D. Zheng, and J. Chen. 2006. Simulating fire spread with landscape management scenarios. For. Sci. 52:522-529.

Loope, L. L. 2000. Vegetation of the Hawaiian Islands. Pages 661-688 in M. G. Barbour and W. D. Billings, eds. North 
American terrestrial vegetation. 2nd ed. Cambridge University Press, Cambridge, United Kingdom.

Maly, K., and B. A. Wilcox. 2000. A short history of cattle and range management in Hawai'i. Rangelands 22 (5): 21-23.

Moody, T. J., and S. L. Stephens. 2000. Methods of FARSITE Simulation and fire risk mapping for Pohakuloa Training Area, Hawaii. Natural Resource Department, California Polytechnic State University, San Luis Obispo.

National Wildfire Coordinating Group. 2002. Gaining an understanding of the National Fire Danger Rating System. P. Schlobohm and J. Brain, comps. NFES 2665, Great Basin Cache Supply Office, Boise, Idaho (http://www.nwcg.gov/pms/ pubs/MasterGaining.pdf).

Ottmar, R. D., D. V. Sandberg, C. L. Riccardi, and S. J. Prichard. 2007. An overview of the Fuel Characteristic Classification System: Quantifying, classifying, and creating fuelbeds for resource planning. Can. J. For. Res. 37:2383-2393.

Parisien, M. A., V. G. Kafka, K. G. Hirsh, J. B. Todd, S. G. Lavoie, and P. D. Maczek. 2005. Mapping wildfire susceptibility with the BURN-P3 simulation model. Can. For. Serv. Inf. Rep. NOR-X-405.

Perry, G. L. W., A. D. Sparrow, and I. F. Owens. 1999. A GIS-supported model for the simulation of the spatial structure of wildland fire, Cass Basin, New Zealand. J. Appl. Ecol. 36:502-518.

Pielou, E. C. 1977. Mathematical ecology. Wiley Interscience, New York.

Roloff, G. J., S. P. Mealey, C. Clay, J. Barry, C. Yanish, and L. Neuenschwander. 2005. A process for modeling short- and longterm risk in the southern Oregon Cascades. For. Ecol. Manage. 211:166-190.

Rossiter, N. A., S. A. Setterfield, M. M. Douglas, and L. B. Hutley. 2003. Testing the grass-fire cycle: Alien grass invasion in the tropical savannas of northern Australia. Divers. Distrib. 9:169-176.

Rothermel, R. C. 1972. A mathematical model for predicting fire spread in wildland fuels. U.S. For. Serv. Res. Pap. INT115 .
Scott, J. H., and R. E. Burgan. 2005. Standard fire behavior fuel models: A comprehensive set for use with Rothermel's surface fire spread model. U.S. For. Serv. Gen. Tech. Rep. RMRS-GTR-153.

Shaw, R. B., and J. M. Castillo. 1997. Plant communities of Pohakuloa Training Area, Hawaii. Center for Ecological Management of Military Lands, Colorado State University, Fort Collins.

Shaw, R. B., J. M. Castillo, and R. D. Laven. 1997. Impact of wildfire on vegetation and rare plants within the Kipuka Kalawamauna Endangered Plants Habitat Area, Pohakuloa Training Area, Hawaii. Pages 253-264 in Proceedings, Fire Effects on Rare and Endangered Species and Habitats Conference, 13-16 November 1995, Coeur d' Alene, Idaho. International Association of Wildland Fire, Fairfield, Washington.

Stephens, M. A. 1986. Tests based on EDF statistics. Pages 97-193 in R. B. D'Agostino and M. A. Stephens, eds. Goodnessof-fit techniques. Marcel Dekker, New York.

Suffling, R., A. Grant, and R. Feick. 2008. Modeling prescribed burns to serve as regional firebreaks to allow wildfire activity in protected areas. For. Ecol. Manage. 256:1815-1824.

U.S. Army. 2003. Integrated Wildland Fire Management Plan, Pohakuloa and Oahu Training Areas, United States Army, Hawaii, and 25th Infantry Division (Light). Prepared by Center for Environmental Management of Military Lands, Colorado State University, Fort Collins, and Installation Fire and Safety Office, U.S. Army, Hawai'i.

U.S. Fish and Wildlife Service. 1986. Recovery plan for the palila. U.S. Fish and Wildlife Service, Portland, Oregon.

Wang, J.-J., H.-M. H. Juang, K. Kodama, S. Businger, Y.-L. Chen, and J. Partain. 1998. Application of the NCEP Regional Spectral Model to improve mesoscale weather forecasts in Hawaii. Weather Forecast. 13:560-575.

Weise, D. R., and F. M. Fujioka. 1998. Comparison of fire spread estimates using 
weather station observations versus nested spectral model gridded weather. 2nd Symposium on Fire and Forest Meteorology, 78th AMS Annual Meeting, 11-16 January 1998, Phoenix, Arizona. 2 October 1997. Preprint volume. Available from the authors.

. 2001. Wildland fire behavior/Fire danger analysis for Pohakuloa Training Area (PTA) 25th Infantry Division (Light) and U.S. Army Hawaii (25thID[L] \& USARHAW). Unpubl. report submitted to U.S. Army. Available from the authors. . 2003. Wildland fire behavior/Fire danger analysis for Pohakuloa Training Area (PTA) 25th Infantry Division (Light) and U.S. Army Hawaii (25thID[L] \& USARHAW). Part II: Fuel moisture models and fire behavior validation. Unpubl. report submitted to U.S. Army. Available from the authors.

Weise, D. R., F. M. Fujioka, and R. M. Nelson Jr. 2005. A comparison of 3 models of 1-hr timelag fuel moisture in $\mathrm{Ha}-$ waii. Agric. For. Meteorol. 133:28-39, doi:10.1016/j.agrformet.2005.03.012

Wright, C. S., R. D. Ottmar, R. E. Vihnanek, and D. R. Weise. 2002. Stereo photo series for quantifying natural fuels: Grassland, shrubland, woodland, and forest types in Hawaii. U.S. For. Serv. Gen. Tech. Rep. PNW-GTR-545. 